\title{
The Nordic Journal of STEM education: An arena for exchange of experience within and across disciplines
}

\author{
Reidar Lyng, NTNU, Trondheim, Norway \\ Mette Mo Jakobsen, Universitets- og høgskolerådet, Oslo, Norway \\ Editorial Team, Nordic Journal of STEM Education
}

With this Journal, we invite you to be part of a growing community of educators that wish to share their experiences of education development of activities, courses and programs according to the principles of Scholarship of Teaching and Learning (SoTL).

This publication has its origins in Norway: within the Norwegian Association of Higher Education Institutions (UHR), there is a National Academic Unit for the STEM-field (UHRMNT) tasked with strengthening higher education, research, development work and innovation in mathematical, science and technology subjects. In 2015 UHR-MNT together with other stakeholders redesigned the bi-annual national conference in the STEM-field (MNT- Konferansen), from a format of mostly invited key-note speakers to a conference where educators presented their experiences in parallel sessions, in a format of SoTL inspired studies. The conference now moves between different institutions, and is organized by a program committee and a review committee. The national body UHR-MNT, the National Center for STEM-Recruitment, and the organizing institution, together with student representation, constitute the program committee. In the review committee peers from the STEM-field, pedagogy and subject didactics, as well as persons with SoTL experience and SFU (centers for excellence in education) experience are involved. The 2015 Conference, titled "Teach Less, Learn More" at the University of Bergen was a success, and the format was repeated in 2017 together with the University of Oslo as under the heading "Transformative Education". The next MNT Conference will take place in 2019 at the Arctic University of Norway, in Tromsø.

As part of the project UHR-MNT took the initiative to establish an Open Access Journal where the conference contributions could be expanded and reworked to full papers. It was desirable to establish a journal with a Nordic perspective. Norway, Sweden and Denmark share a fair common understanding of language, culture and educational structure and it was decided that the editorial board should have representatives from all three Nordic countries, and that the articles would be accepted in any one of the three languages, or in English.

As a community within the fields of STEM, we are aiming for a cultural shift concerning teaching and learning, inspired by the research culture - Scholarship of Teaching and Learning, SoTL. This implies to go from teaching as private, with little peer interaction or documentation, to teaching as collegial, peer reviewed and well documented. Further focus must shift from teaching to student learning. The Nordic Journal of STEM education aim to support this process. 